\begin{tabular}{|c|c|c|}
\hline Case Reports in & \multicolumn{2}{|c|}{ Case Rep Gastroenterol 2019;13:195-199 } \\
\hline Gastroenterology & $\begin{array}{l}\text { DOl: 10.1159/000499444 } \\
\text { Published online: April 9, } 2019\end{array}$ & $\begin{array}{l}\text { (c) } 2019 \text { The Author(s) } \\
\text { Published by S. Karger AG, Basel } \\
\text { www.karger.com/crg }\end{array}$ \\
\hline & $\begin{array}{l}\text { This article is licensed under } \\
\text { International License (CC BY- } \\
\text { Usage and distribution for com }\end{array}$ & $\begin{array}{l}\text { nons Attribution-NonCommercial } 4.0 \\
\text { ger.com/Services/OpenAccessLicense). } \\
\text { uires written permission. }\end{array}$ \\
\hline
\end{tabular}

\title{
Autoimmune Pancreatitis Type 1 Associated with a Pancreatic Pseudocyst
}

\author{
Felix Hesse $^{a} \quad$ Rickmer Braren $^{b} \quad$ Roland M. Schmid ${ }^{a} \quad$ Veit Phillip ${ }^{a}$ \\ aKlinik und Poliklinik für Innere Medizin II, Klinikum rechts der Isar der Technischen \\ Universität München, Munich, Germany; ' Institut für Diagnostische und Interventionelle \\ Radiologie, Klinikum rechts der Isar der Technischen Universität München, \\ Munich, Germany
}

\section{Keywords}

Autoimmune pancreatitis · Corticosteroid · Pancreatic pseudocyst

\begin{abstract}
Pancreatic cystic lesions comprise diverse entities with different histopathological characteristics. Differential diagnosis is often challenging. Autoimmune pancreatitis (AIP) is usually not considered an underlying pathology in the differential diagnosis of peri-/pancreatic pseudo/cystic lesions. We report the case of a 73-year-old male with diffuse pancreatic enlargement and an adjacent cystic lesion $(60 \times 80 \mathrm{~mm})$ on computed tomography scan. Based on these imaging findings and an elevated serum IgG4 concentration, AIP complicated by a pancreatic pseudocyst was diagnosed, and treatment with glucocorticoids was started. Regular followups showed a good response to treatment with regression of the pancreatic pseudocyst and remittent pancreatic swelling.

(C) 2019 The Author(s) Published by S. Karger AG, Basel
\end{abstract}

\section{Introduction}

Autoimmune pancreatitis (AIP) is a fibroinflammatory disorder of presumed autoimmune etiology that is associated with characteristic clinical, histologic, and morphologic findings $[1,2]$. Incidence and prevalence are yet undetermined; however, the prevalence rate of 


\section{Case Reports in Gastroenterology}

Case Rep Gastroenterol 2019;13:195-199

DOI: $10.1159 / 000499444$

(c) 2019 The Author(s). Published by S. Karger AG, Basel www.karger.com/crg

Hesse et al.: Autoimmune Pancreatitis Type 1 Associated with a Pancreatic Pseudocyst

AIP may account for $9 \%$ of the patients with nonalcoholic pancreatitis but is almost never observed in patients with alcoholic pancreatitis. Several publications have indicated that AIP type 1 is part of a systemic IgG4-related disease [3]. Clinical manifestations of AIP are varied and include mild, recurrent pancreatitis, pancreatic duct strictures but mild upstream dilation, diffuse sausage-like enlargement of the pancreas, and a pancreatic mass on imaging. Diagnostic criteria of AIP are summarized in the HISORt criteria, the Japan consensus criteria and the "International Consensus Diagnostic Criteria" from the International Association of Pancreatology and comprise histology, characteristic imaging, elevated serum IgG4 levels on serologic testing, other organ involvement (biliary strictures, parotid/lacrimal gland involvement, mediastinal lymphadenopathy, retroperitoneal fibrosis), and response of pancreatic and extrapancreatic manifestations to glucocorticoid therapy [4]. First-line treatment is corticosteroids with a response rate of up to $98 \%$ [5]. Therapy should be started with prednisone at a dosage of $40 \mathrm{mg}$ daily for 4 weeks followed by a taper of $5 \mathrm{mg} /$ week [6]. While most patients initially respond well to glucocorticoids, a significant proportion of patients relapse once treatment is discontinued. Options are repeat course, maintenance therapy, or considering immunomodulators [7-9]. Complications of AIP comprise endocrine and exocrine failure, whereas pancreatic pseudocysts are very seldom [10]. Here, we report a case of AIP type 1 complicated by a large pancreatic pseudocyst and complete dissolving after steroid therapy.

\section{Case Presentation}

A 73-year-old male was referred to our department by Helios Clinic München Perlach with a high-grade suspicion of AIP. First presentation revealed painless jaundice, diarrhea, and a weight loss of 5\% within 4 weeks. The initial body weight was $86 \mathrm{~kg}$. There was no evidence of fever or abdominal pain. The patient did not have any history of alcohol abuse or previous liver or pancreatic diseases. Routine laboratory analysis showed increased liver function test results (alkaline phosphatase $781 \mathrm{U} / \mathrm{L}$; aspartate aminotransferase $320 \mathrm{U} / \mathrm{L}$; alanine aminotransferase $698 \mathrm{U} / \mathrm{L}$; gamma glutamyl transferase 1,441 U/L; total bilirubin 6.02 $\mathrm{mg} / \mathrm{dL}$ ) and an elevated serum IgG4 concentration (1,190 mg/dL; normal range 3-200). Computed tomography revealed a diffusely enlarged pancreas ("sausage-like" with loss of lobulation), hypoattenuating, with adjacent edema and a cystic lesion $(60 \times 80 \mathrm{~mm})$ extending from the pancreatic tail (Fig. 1). Before presenting at our department, the patient underwent biliary stenting due to extrahepatic cholestasis. Based on these findings, the patient was diagnosed with AIP and a pancreatic pseudocyst. A corticosteroid therapy was initiated with 40 mg prednisolone daily and tapered gradually for 30 weeks until drug discontinuation. Magnetic resonance imaging, performed after 6 months of therapy revealed a partial normalization of the pancreas with a remaining prominent duct, and partial regression of the pancreatic pseudocyst $(26 \times 11 \mathrm{~mm}$ ) (Fig. 2). Consistently, serum IgG4 concentration also declined to $292 \mathrm{mg} / \mathrm{dL}$ after 4 weeks of prednisolone therapy and $159 \mathrm{mg} / \mathrm{dL}$ after 16 weeks of therapy (Fig. 3).

\section{Discussion}

Differentiating cystic pancreatic lesions remains a clinical challenge. In 1995, Yoshida et al. [11] reported that one of the characteristic features of AIP is the absence of pancreatic cysts. Here, we report a rare case of AIP associated with a pancreatic cyst, highly suggestive of a 
pseudocyst based on the initial imaging presentation. Only few reports describing AIP complicated by a pseudocyst are published in the literature [12,13]. Upon corticosteroid-based therapy, pancreatic swelling and the pseudocyst resolved without the need for drainage. Kawakami et al. [14] suggested that corticosteroid treatment should be started immediately upon appearance of a pseudocyst in AIP, as this may resolve under treatment. Cyst formation in AIP might represent a highly active inflammatory process $[13,15]$. We found a high serum IgG4 concentration that closely correlates with the active state of this disease. The exact mechanism of the pathogenesis of the cyst is not completely understood, but stenosis of the pancreatic duct may have caused reduced drainage of pancreatic juice resulting in the pancreatic pseudocysts. Corticosteroids may induce pseudocyst regression through inhibition of inflammation of the pancreatic duct, thus reducing the stenosis and improving the drainage of pancreatic juice. In summary, our report shows the importance of including AIP as an underlying pathology in the early differential diagnosis of cystic pancreatic lesions and suggests that the pancreatic pseudocysts in patients with AIP can be treated successfully without invasive therapy. Corticosteroid therapy should be started immediately, and response to treatment should be controlled by regular imaging.

\section{Statement of Ethics}

Written informed consent was obtained from the patient.

\section{Disclosure Statement}

All authors have no conflicts of interest to disclose.

\section{Author Contributions}

Felix Hesse: Drafting the work and substantial contributions to the acquisition, analysis, and interpretation of data for the work.

Rickmer Braren: Substantial contributions to the conception of the work and analysis, such as the interpretation of data for the work.

Roland M. Schmid: Revising the work critically for important intellectual content, such as final approval of the version to be published.

Veit Phillip: Substantial contributions to the conception and design of the work, such as revising it critically for important intellectual content.

\section{References}

1 Rasch S, Phillip V, Schmid RM, Algül H. Epidemiology, clinical presentation, diagnosis and treatment of autoimmune pancreatitis: A retrospective analysis of 53 patients. Pancreatology. 2016 Jan-Feb;16(1):73-7.

2 Finkelberg DL, Sahani D, Deshpande V, Brugge WR. Autoimmune pancreatitis. N Engl J Med. 2006 Dec;355(25):2670-6.

3 Kamisawa T, Egawa N, Nakajima H. Autoimmune pancreatitis is a systemic autoimmune disease. Am J Gastroenterol. 2003 Dec;98(12):2811-2.

4 Chari ST, Smyrk TC, Levy MJ, Topazian MD, Takahashi N, Zhang L, et al. Diagnosis of autoimmune pancreatitis: the Mayo Clinic experience. Clin Gastroenterol Hepatol. 2006 Aug;4(8):1010-6, quiz934. 


\section{Case Reports in Gastroenterology}

Hesse et al.: Autoimmune Pancreatitis Type 1 Associated with a Pancreatic Pseudocyst

5 Kamisawa T, Shimosegawa T, Okazaki K, Nishino T, Watanabe H, Kanno A, et al. Standard steroid treatment for autoimmune pancreatitis. Gut. 2009 Nov;58(11):1504-7.

6 Sah RP, Chari ST. Autoimmune pancreatitis: an update on classification, diagnosis, natural history and management. Curr Gastroenterol Rep. 2012 Apr;14(2):95-105.

7 Hirano K, Tada M, Isayama H, Yagioka H, Sasaki T, Kogure H, et al. Long-term prognosis of autoimmune pancreatitis with and without corticosteroid treatment. Gut. 2007 Dec;56(12):1719-24.

8 Raina A, Yadav D, Krasinskas AM, McGrath KM, Khalid A, Sanders M, et al. Evaluation and management of autoimmune pancreatitis: experience at a large US center. Am J Gastroenterol. 2009 Sep;104(9):2295-306

9 Kamisawa T, Okazaki K, Kawa S, Ito T, Inui K, Irie H, et al.; Working Committee of the Japan Pancreas Society and the Research Committee for Intractable Pancreatic Disease supported by the Ministry of Health, Labour and Welfare of Japan. Amendment of the Japanese Consensus Guidelines for Autoimmune Pancreatitis, 2013 III. Treatment and prognosis of autoimmune pancreatitis. J Gastroenterol. 2014 Jun;49(6):961-70.

10 Donet JA, Barkin JA, Keihanian T, Nemeth Z, Barkin JS. Pancreatic Pseudocysts and Parenchymal Necrosis in Patients With Autoimmune Pancreatitis: A Systematic Review. Pancreas. 2018 Sep;47(8):952-7.

11 Yoshida K, Toki F, Takeuchi T, Watanabe S, Shiratori K, Hayashi N. Chronic pancreatitis caused by an autoimmune abnormality. Proposal of the concept of autoimmune pancreatitis. Dig Dis Sci. 1995 Jul;40(7):1561-8.

12 Nishimura N, Tamada K, Wada S, Ohashi A, Hatanaka H, Nakazawa K, et al. Autoimmune pancreatitis associated with a large pancreatic pseudocyst that disappeared after corticosteroid therapy: a case report and literature review. Clin J Gastroenterol. 2009 Jun;2(3):199-203.

13 Muraki T, Hamano H, Ochi Y, Arakura N, Takayama M, Komatsu K, et al. Corticosteroid-responsive pancreatic cyst found in autoimmune pancreatitis. J Gastroenterol. 2005 Jul;40(7):761-6.

14 Kawakami H, Kuwatani M, Shinada K, Yamato H, Hirano S, Kondo S, et al. Autoimmune pancreatitis associated with hemorrhagic pseudocysts: a case report and literature review. Intern Med. 2008;47(7):6038.

15 Sohn JW, Cho CM, Jung MK, Park SY, Jeon SW. A Case of Autoimmune Pancreatitis Manifested by a Pseudocyst and IgG4-Associated Cholangitis. Gut Liver. 2012 Jan;6(1):132-5.

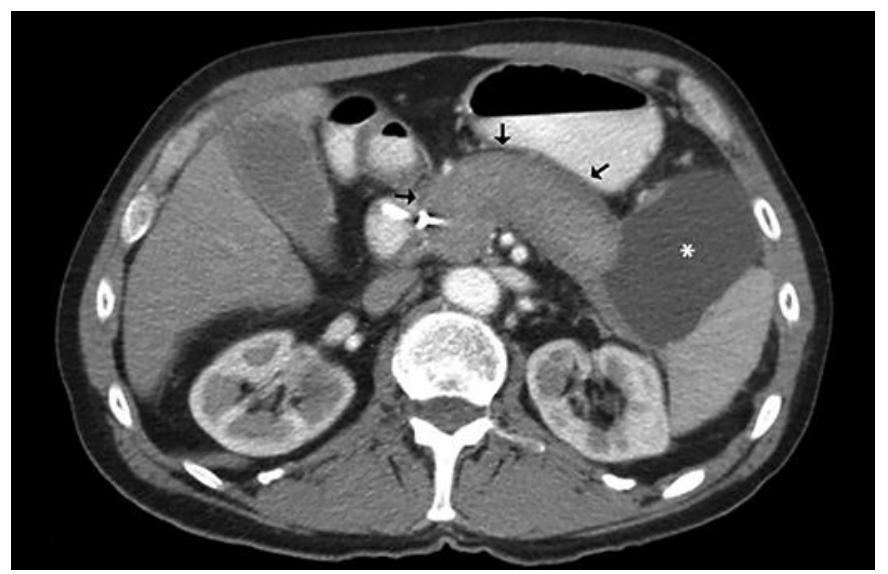

Fig. 1. Contrast-enhanced computed tomography scan showing sausage-like enlargement with homogenous attenuation of the pancreas, a peripheral rim of hypoattenuation "halo," a loss of lobulation (arrows), and a caudally situated cystic lesion $(60 \times 80 \mathrm{~mm}$; asterisk). 


\section{Case Reports in Gastroenterology

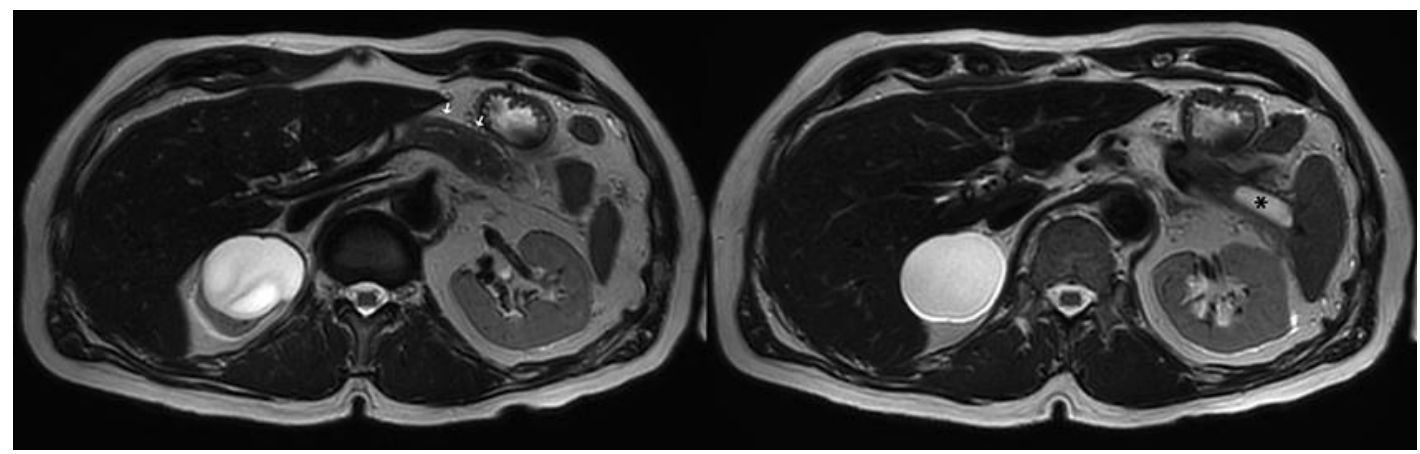

Fig. 2. Magnetic resonance imaging on T2-weighted sequences 6 months after initiation of therapy showing a less swollen pancreas with a prominent pancreatic duct (arrows) and a reduction in size of the caudally situated cystic lesion $(26 \times 11 \mathrm{~mm}$; asterisk).

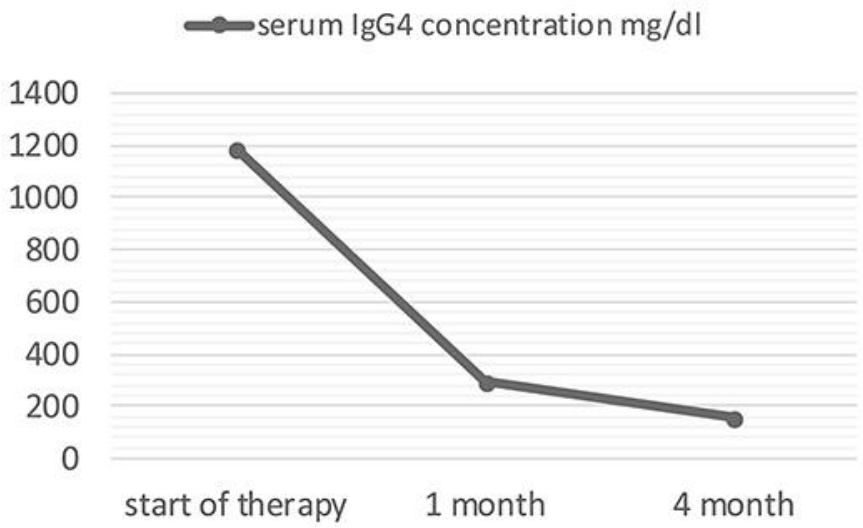

Fig. 3. Graph showing declining IgG4 levels during the therapy. 